\title{
Spatial Trends of Urban Physical Growth of Cities in Java, Indonesia, 1975-2015
}

\author{
Djaka Marwasta \\ Department of Environmental Geography, Faculty of Geography, Universitas Gadjah Mada, Sekip Utara, Bulaksumur, Yogyakarta 55281, \\ Indonesia
}

Corresponding author: jakamar@ugm.ac.id

\author{
KEYWORDS \\ Multi-temporal satellite \\ image \\ Urban extensification \\ Urban morphology
}

\begin{abstract}
This paper discusses the spatial trends of urban physical growth of several cities in Java. Six cities in Java (Jakarta, Bandung, Semarang, Yogyakarta, Surabaya, and Malang) were chosen as samples to represent the characteristics of cities in Java based on their geographic settings, including their topography, size, population density, and history of their development. The objectives of this study were: (1) to understand the variations in physical growth of cities in Java; and (2) to explain the spatial trends of urban physical growth of these cities based on their geographic settings. Multi-temporal Landsat satellite images were chosen as data sources to identify urban morphological development processes. Based on results of analysis, it was found that the physical growth of cities in Java has had relatively diverse variations in the aspects of urban settlements, infrastructure, and urban functions. However, the diversity of urban physical growth can be simplified into four types based on the dominant form of physical development. These four types were found to be (1) a compact-rounded city that is formed by the domination of a densification process; (2) a spread-elongated city formed by the dominance of an extensification process; (3) a compact fan-shaped city that is formed by natural physical conditions; and (4) a scattered-random city formed by the domination of a leapfrogging process.
\end{abstract}

(c) The Author(s) 2019. This article is distributed under a Creative Commons Attribution-ShareAlike 4.0 International license.

\section{INTRODUCTION}

The world has experienced urban population growth faster than what is predicted by Malthus, known as the Limits of Growth. In 1950, there were only 86 cities in the world with a population of more than 1 million. This number has since reached 550 cities. The proportion of the urban population to the total world population, the United Nation notes, rose from $13 \%$ (220 million) in the beginning of the 1900s to $29 \%$ (732 million) in 1950, and then increased significantly to $49 \%$ ( 3.2 billion) in 2005 . The United Nation predicts that in 2030 the proportion of the urban population will reach $60 \%$ (4.9 billion people). Highlighting this dramatic increase, in 2005 the total urban population was greater than the total world population in 1960 (Douglass 1998).

Urbanization is the most dominant process responsible for the increase in urban population proportion. It should be noted that the rapid rate of urbanization is dominated by developing countries, especially the Asia Pacific. Data show that the proportion of the urban population in the Asia Pacific region was $35 \%$ of the total population in the early 1990 s, and increased at a rate of $3.2 \%$ per year during the period 1990-1995. It is an irony that urbanization, which is the direct impact of the industrialization process, is more dominant in high-level escalations in countries that tend to be less successful in becoming industrial countries. For example, Indonesia during the 1996-2006 period actually experienced de-industrialization, and even if there was progress in the industrial sector, it occurred in the smallscale household industry sector and MSMEs.
The impact of a high rate of urbanization (in a broad sense, not only that concerning the exodus of rural residents to urban areas) is the increasing need for land for settlements and other urban functions around large cities. In Indonesia, this phenomenon has been very evident in the cities of Java that have very large populations. The impact of this situation is the invasion of urban land use on the city outskirts to fertile agricultural land, thus causing a decrease in agricultural production and productivity and social conflict in peri-urban areas, as well (Burchell et al. 1998; Seto et al. 2009).

Urban physical development (referred to as "urban spatial growth" in this paper) is a consequence of urban growth. The terminology of urban growth refers to the process of growing and shrinking urban economic agglomeration (Fujita et al. 2001). The pattern of concentration of economic activity is an important determinant of ongoing urbanization, city structure, and spatial growth of cities (Fujita et al. 2001). In order to reduce the impact in the very large exhalation of many populated cities in Java, it is necessary to control the spatial growth of these cities, and for this purpose, this study is needed to monitor their growth process.

Measuring the spatial growth of cities is not an easy task, because the definition and boundaries of urban areas are very diverse and dynamic according to time. An easy-to-use approach is to combine administrative boundaries with morphological constraints. To support the study of spatial growth processes in urban areas, multi-temporal data are needed that have spatial references standard. In this area, remote sensing satellite image data have proved 
to be reliable (Wilson et al. 2003; Bianchin and Bravin 2004; Roca et al. 2004; Moeller 2005).

The importance of this research is related to the SDG's agenda in the urban field, namely the realization of the ecocity concept. The concept of the eco-city originates from the fundamental objective of sustainability and the application of ecological principles to urban planning, design, and management. In this concept, there are three essential components that must be present in order for it to be regarded as a sustainable eco-city. The first, on the environmental front, is that the eco-city must be able to protect or preferably even enhance the environment. Within the eco-city, there ought to be important aspects or features such as the application of green technologies, environmentally sustainable transportation, rational use of space, green belts and parks, and cultural and heritage conservation. On the whole, the eco-city should strive towards producing a lower ecological footprint.

The second component comprises the economic aspect, wherein the eco-city must be able to contribute to economic growth by attracting investment and generating revenue and jobs. Economic growth will provide the necessary resources to better protect the environment by raising the living standards of inhabitants. The greater the prosperity and better the living standards, the more aware and supportive the populace will be of efforts to safeguard the environment.

The final component is the social and cultural front. The eco-city must be able to meet social considerations, for instance strengthening the bonds of friendship and unity among social groups. The eco-city should be accessible to people from various walks of life. The concept of the ecocity is illustrated in Figure 1.

\section{METHODS}

The research method used was exploratory descriptive research. The data used in this study were Landsat Satellite data for the 1970-1980s period, 1990-2000s period, and 2010-2015 period. Other data were also used, namely basic maps that were used as spatial references, in this case the map being the Indonesian Topographic Map (RBI) at a scale of 1:25,000. Information on road networks, river networks, administrative boundaries, and toponyms were taken from the RBI map.

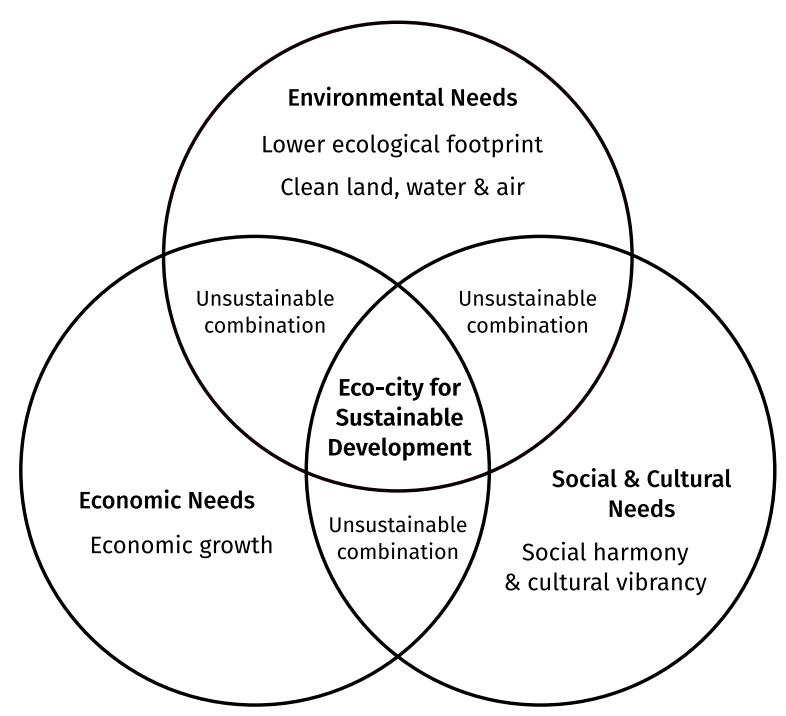

FIGURE 1. Eco-city concept.
Digital image processing was also used. The digital analysis technique used was the transformation model, which is a built-in land index (NDBI) formula that is integrated with the Normalized Difference Vegetation Index (NDVI), Soil Adjusted Vegetation Index (SAVI), and Modified Normalized Difference Water Index (MNDWI). NDBI is a multispectral transformation model that produces new pixel values in the form of indices that highlight building cover information and built-up land. NDVI is a multispectral transformation model that produces new pixel values that highlight vegetation cover information. SAVI is a multispectral transformation model that produces new pixel values that highlight soil cover information. MNDWI is a multispectral transformation model that produces new pixel values that indice water features.

The results of integrating NDBI, NDVI, SAVI, and MNDWI formulations produced a map of built-up land (in this study it was assumed to be the urban morphological boundary). The multi-time city morphological boundary map collated with the administrative boundary map of each city will produce a typology of urban spatial growth. The standard used was the built-up area $>75 \%$. The morphological maps of the cities in each year $(1975,1995$, and 2015) were subsequently stacked to produce urban morphological development maps.

Based on the urban morphological development maps, descriptive analysis of spatial trends was conducted. Analysis of urban development spatial trends used a "wind rose" model to describe spatial development orientation. The results of the descriptive analysis of urban spatial growth were then compared with the population growth of the city to understand the relationship between them. The trend analysis was carried out based on the homogeneity of the additional rate of urban built-up land area over time, spatial orientation, the linkages with major transportation routes, and population dynamics.

\section{RESULTS AND DISCUSSIONS}

This research was conducted on six cities in Java Island, namely Jakarta, Surabaya, Bandung, Semarang, Malang, and Yogyakarta. Jakarta and Bandung are located in the western part of Java, Semarang and Yogyakarta in the center of Java, Surabaya and Malang are two cities located in the eastern part of Java. These six cities were chosen based on city rankings in Java, as well as based on various considerations of physical and social characteristics. Table 1 shows the ranking of the city hierarchy in Java.

As the capital city of Indonesia, Jakarta is of course ranked first in the city hierarchy, and is a primate city not only in Java, but also in Indonesia. This is reflected in the population of Jakarta amounting to three times that of Surabaya, the second most populous city. From the primacy index, it is also seen that Jakarta's hegemony is still very strong and tends to be stronger, whereas Surabaya and Yogyakarta have tended to decline, and the other cities have been relatively stagnant.

Of the six cities, in general, the city's population growth within administrative boundaries did not show a high rate. This condition is contrary to the built-up area growth inside and outside the boundaries of the city administration. This condition shows that the rate of urban spatial growth is not only determined by the rate of population growth in the city. In other words, urban population growth is not always coincident with urban spatial growth. The law that applies here is that high urban growth will be accompanied by high spatial growth of cities (both horizontal and verti- 
TABLE 1. Cities' Primacy Index in Java, Indonesia.

\begin{tabular}{|c|c|c|c|c|c|c|c|}
\hline \multirow[t]{2}{*}{ Rank } & \multirow[t]{2}{*}{ City } & \multicolumn{3}{|c|}{ Total Population } & \multicolumn{3}{|c|}{ Primacy Index } \\
\hline & & 1971 & 1990 & 2010 & 1971 & 1990 & 2010 \\
\hline 1 & Jakarta & $4,579,303$ & $8,222,515$ & $9,567,127$ & 0.47 & 0.51 & 0.50 \\
\hline 2 & Surabaya & $1,549,212$ & $2,483,871$ & $2,765,908$ & 0.16 & 0.15 & 0.14 \\
\hline 3 & Bandung & $1,200,380$ & $2,058,122$ & $2,393,633$ & 0.12 & 0.13 & 0.12 \\
\hline 4 & Semarang & 641,795 & $1,249,230$ & $1,553,778$ & 0.07 & 0.08 & 0.08 \\
\hline 5 & Malang & 421,577 & 636,308 & 819,708 & 0.04 & 0.04 & 0.04 \\
\hline 6 & Yogyakarta & 340,192 & 412,059 & 388,088 & 0.04 & 0.03 & 0.02 \\
\hline
\end{tabular}

cal), but high spatial growth of cities is not always caused by high urban growth.

Jakarta experienced urban spatial growth from 1975 to 2015 , tending to all directions (except to the north) in high intensity. Developments from 1975 to 1995 were characterized by concentric fan-shaped and leapfrog types that were marked by the emergence of built-up land located far from the administrative boundary. The development of 1995-2015 was dominated by concentric types and built-up densification combined with the leapfrogging development. This process gave Jakarta a compact fan shape because it is influenced by bordering the coast in the north (Figure 2).

Based on previous literature, urban spatial development is divided into five types, namely: organic (infill), expansion, isolated, linear branch, and clustered branch (Wilson et al. 2003; Sun et al. 2015). Organic growth is characterized by the presence of small, newly built land between existing urban land uses (Sun et al. 2015). Some papers have called it the densification process. The expansive type is characterized by the presence of new, built-up land outside and attached to existing urban land use, converting non-urban lands (built-up area $<40 \%$ ). Humphrey Carver explains that this type produces belts along rural areas around urban areas (Heimlich and Anderson 2001). This type is also known as the urban fringe development (Heim- lich and Anderson 2001; Theobald 2001). Organic and expansive types occur in existing built areas.

Three other types occur outside existing urban areas, and are generally known as outlying growth. In general, the region experiencing this growth process is characterized by changes in the use of non-urban land into urban interiors. Isolated growth is characterized by the emergence of buildings in areas that are far from the city on non-urban land use. Linear branch growth is characterized by new transportation routes in non-urban areas that are some distance from the existing city. Clustered branch growth is characterized by a group of new settlements (a complex new neighborhood) on non-urban land far from the city. Harvey and Clark (1965) defined it as the growth of leapfrog development.

Surabaya also experienced urban spatial growth from 1975 to 2015 in high intensity, but this growth did not occur in all directions. The development of Surabaya in 1975-1995 and 1995-2015 took place axially, to the northwest and to the south. Pseudo concentric infiltration also occurred to the east. This process resulted in the Surabaya urban area having an octopus-like shape, with northwest and south direction (Figure 2).

Bandung grew outward in quite low intensity in the 1975-1995 and 1995-2015 periods, as well (see also Figure
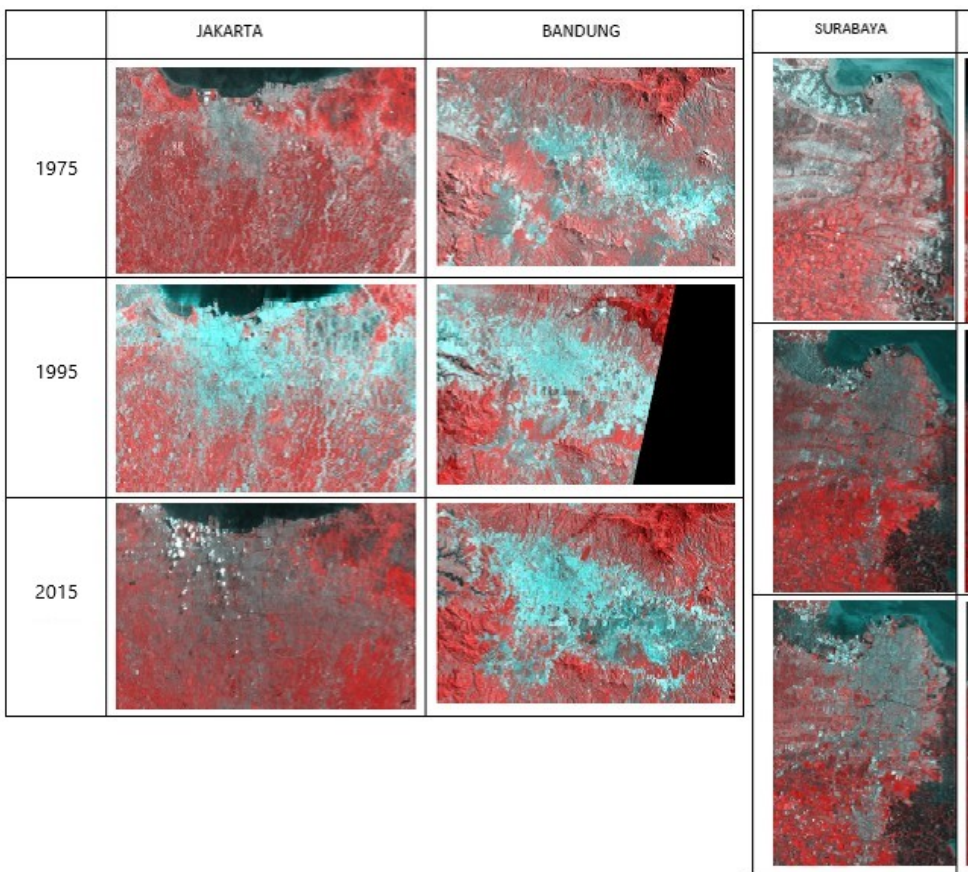

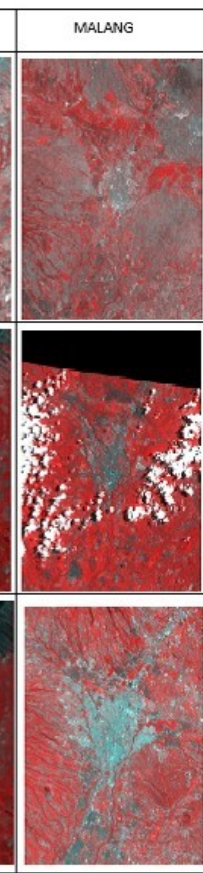

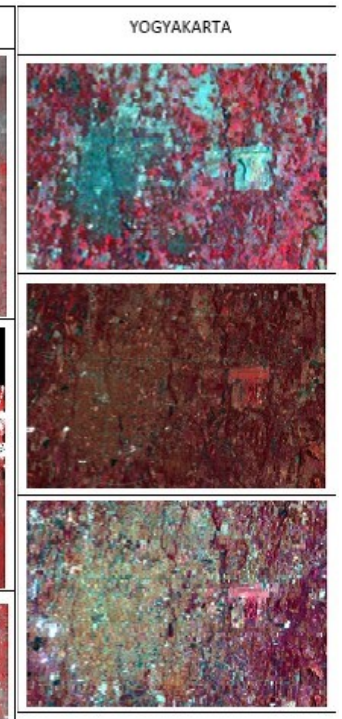

FIGURE 2. Landsat satellite images of six cities in Java, Indonesia, in the years 1975, 1995, and 2015. 
2). The spatial development of the Bandung urban area was dominated by densification (organic growth) within the limits of the city administration. The morphology of the Bandung urban area internally tended to be shaped like an octopus, and in some parts there was a process of leapfrogging. In general, Bandung is a type of city that spreads randomly to the northwest, north, northeast, southeast, and southwest directions, so that the spatial development path is similar to a star shape.

Semarang experienced physical growth in moderate intensity, both in the 1975-1995 period and 1995-2015 period. The development occurred semi-concentrically, with the dominant direction being to the south, and linear to the west and east. The dominance of urban spatial growth was a combination of ribbon patterns with the direction of the east-west axis and semi-concentric to the south. The shape of the city that emerged from the process was a compact city fan shape (Figure 2).

Malang grew spatially following concentric types in moderate intensity in the 1975-1995 and 1995-2015 periods, as well. This concentric development followed the initial form of the city, which tended to be rectangular. Another development that occurred was extension to the northeastsouthwest, although the intensity was not high. The morphological type of Malang was compact rounded (Figure 2).

Yogyakarta developed concentrically in low intensity between 1975 and 1995, and in high intensity between 1995 and 2015. The development in all directions was supported by physiographic conditions that tended to be homogeneous in all directions. However, the intensity of land development was not similar in all directions. Instead, development to the northeast and west had a higher intensity than the other directions. The shape of the city produced from this process was a compact type (Figure 2).

In general, the trend of the urban morphological development of the cities in Java can be grouped into four types, namely compact rounded, spread-elongated, compact fanshaped, and scattered-random. A compact rounded city is formed by the domination of a densification process. Yogyakarta and Malang, as such, are examples of this type of spatial trend development. The spread-elongated city formed by the dominance of an extensification process, as exemplified by both Jakarta and Surabaya.

A compact fan-shaped city is formed by natural physical conditions, of which Semarang is an example. And finally, the scattered-random type is formed by a leapfrogging process's domination. Bandung is an example of scattered-random spatial development in an urban area.

\section{CONCLUSIONS}

The urban physical growth of cities in Java since the 1970s has been very diverse. In the 1975-1995 period, they commonly grew in low intension, even varying in intensity of growth. However, in the 1995-2015 period, some cities grew very fast, some cities grew with medium intensity, and the rest experienced quite low growth. The urban physical growth of these Javanese cities also had quite di- verse variations in terms of their spatial trends. In general, four types of spatial trends-compact rounded, spreadelongated, compact fan-shaped, and scattered-randomdominated urban spatial development in Java.

\section{REFERENCES}

Bianchin A, Bravin L. 2004. Defining and detecting changes in urban areas. Int Arch Photogramm Remote Sens Spat Inf Sci. 35(7):466-471. https://www.isprs.org/procee dings/XXXV/congress/comm7/papers/91.pdf.

Burchell RW, Shad NA, Listokin D, Phillips H, Downs A, Seskin S, Davis JS, Moore T, Helton D, Gall M. 1998. The costs of sprawl-revisited. Transit Cooperative Research Program Report 39. Transportation Research Board. Washington, DC.

Douglass M. 1998. A regional network strategy for reciprocal rural-urban linkages: an agenda for policy research with reference to Indonesia. In: Tacoli C, editor. The Earthscan reader in rural-urban linkages. London: Routledge. p. 124-154. doi:10.4324/9781315800486-7.

Fujita M, Krugman P, Venables A. 2001. The spatial economy: cities, regions, and international trade. 1st edition. Cambridge: The MIT Press.

Harvey RO, Clark WAV. 1965. The nature of economics and urban sprawl. Land Econ. 41(1):1-9.

Heimlich RE, Anderson WD. 2001. Development at the urban fringe and beyond: impacts on agriculture and rural land. doi:10.22004/ag.econ.33943.

Moeller MS. 2005. Remote sensing for the monitoring of urban growth patterns. Int Arch Photogramm Remote Sens Spat Inf Sci. XXXVI-8/W27. https://www.isprs. org/proceedings/XXXVI/8-W27/moeller.pdf.

Roca J, Burns MC, Carreras JM. 2004. Monitoring urban sprawl around Barcelona's metropolitan area with the aid of satellite imagery. Proceedings of Geo-Imagery Bridging Continents, $\mathrm{XX}^{\text {th }}$ ISPRS Congress; Istanbul, Turkey.

Seto KC, Fragkias, Guneralp B, Reilly M. 2009. Rapidly growing cities and their resilience to climate change: a metaanalysis of global trends in urban land-use change and indicators of resilience and vulnerability. IOP Conf Ser: Earth Environ Sci. 6(33):332010. doi:10.1088/1755-130 7/6/33/332010.

Sun Y, Zhao S, Qu W. 2015. Quantifying spatiotemporal patterns of urban expansion in three capital cities in Northeast China over the past three decades using satellite data sets. Environ Earth Sci. 73(11):7221-7235. doi:10.1007/s12665-014-3901-6.

Theobald DM. 2001. Land-use dynamics beyond the American rural fringe. Geogr Rev. 91(3):544-564. doi:10.1111/ j.1931-0846.2001.tb00240.x.

Wilson EH, Hurd JD, Civco DL, Prisloe MP, Arnold C. 2003. Development of a geospatial model to quantify, describe and map urban growth. Remote Sens Environ. 86(3):275-285. doi:10.1016/S0034-4257(03)00074-9. 